ORIGINAL ARTICLE

\title{
Characterisation of adherens and tight junctional molecules in normal animal larynx; determining a suitable model for studying molecular abnormalities in human laryngopharyngeal reflux
}

\author{
G A Gill, A Buda, M Moorghen, P W Dettmar, M Pignatelli
}

J Clin Pathol 2005;58:1265-1270. doi: 10.1136/icp.2004.016972

See end of article for authors' affiliations .....................

Correspondence to: Professor M Pignatelli, Department of Pathology and Microbiology, Division of Histopathology, Bristol Royal Infirmary,

Marlborough Street, Bristol BS2 8HW, UK; massimo. pignatelli@bristol.ac.uk

Accepted for publication 7 July 2004
Background: The disruption of intercellular junctions in the larynx is a pathological feature of laryngopharyngeal reflux (LPR). Good experimental models are necessary to gain greater insight into the molecular mechanisms and alterations that result from abnormal exposure of the laryngeal epithelium to acid refluxate.

Aims: To characterise laryngeal tissues from different species to determine the most suitable for use in experimental studies of LPR.

Methods: Human and non-human laryngeal tissues (mouse, rat, guinea pig, porcine, and rabbit) were studied. Histological characterisation was performed by light microscopy. The expression and subcellular localisation of adherens junctional molecules (E-cadherin and $\beta$ catenin) was evaluated by immunohistochemistry, and tight junction molecules (occludin and zonula occludens 1 (ZO-1)) by western blotting. The ultrastructural features of porcine and human tissue were assessed by electron microscopy. Results: Porcine tissue revealed both respiratory-type and stratified squamous epithelium, as seen in the human larynx. The expression and subcellular localisation of the E-cadherin-catenin complex was detected in all species except mouse and rat. The pattern of ZO-1 and occludin expression was preserved in all species.

Conclusion: The expression of intercellular junctional complexes in porcine epithelium is similar to that seen in humans. These results confirm the suitability of these species to study molecular mechanisms of LPR in an experimental system.

\section{(1)} aryngopharyngeal reflux (LPR) has gained increased recognition over recent years. ${ }^{1-8}$ Acid refluxate is known Lto contribute to the development of many otolaryngological symptoms and conditions, including laryngitis, sore throat, contact ulcers, and globus pharyngeus. ${ }^{9}$ However, to date, very little has been published in relation to the molecular mechanisms or alterations that result from abnormal exposure of acid refluxate on the laryngeal epithelium.

\begin{abstract}
"Acid refluxate is known to contribute to the development of many otolaryngological symptoms and conditions, including laryngitis, sore throat, contact ulcers, and globus pharyngeus"
\end{abstract}

The pathophysiology and molecular mechanisms of LPR are not completely understood. Both LPR and gastrooesophageal reflux disease (GORD) are caused by acid and pepsin exposure. ${ }^{40}$ However, a direct association between mucosal findings and uncontrolled reflux in the larynx has not been established. ${ }^{11}$ It is probable that acidified pepsin causes a break in the barrier function through an alteration in the intercellular junctional complex, as has been documented in the oesophagus. ${ }^{12-16}$ Indeed, we have recently shown that laryngeal E-cadherin expression is reduced or partially lost in laryngeal biopsies from patients with documented LPR. ${ }^{17}$

Intercellular junctions are composed of adherens junctions (E-cadherin-catenin complexes) and tight junction mole- cules. ${ }^{18-23}$ Adherens junctions represent a large family of transmembrane glycoproteins (cadherins) responsible for calcium dependant intercellular adhesion and interaction. ${ }^{24-27}$ In particular, they are important for processes such as migration and restitution after damage. The tight junction complex consists of several cytoplasmic and membrane proteins, including zonula occludens 1 (ZO-1), and occludin, and is localised to the boundary of the apical and basolateral plasma membrane domains of epithelial cells. ${ }^{28-34}$ The tight junction complex forms a primary barrier to the passage of solutes through the paracellular space.

Good animal models are essential aids in the study of laryngeal pathophysiology. Concern exists, however, regarding the suitability of models because of both gross anatomical and histological differences to the human larynx. The aim of our study was to characterise the intercellular adhesion molecules in the laryngeal epithelium of several species and compare them with those seen in humans to identify the most suitable animal model for experimental studies on laryngeal reflux.

\section{MATERIALS AND METHODS}

Tissue specimens

Laryngeal tissue from non-human species (mouse, rat, guinea pig, pig, and rabbit) was obtained from the department of veterinary pathology, Langford, UK. Anonymised human laryngeal tissue samples were obtained from the

Abbreviations: GORD, gastro-oesophageal reflux disease; LPR, laryngopharyngeal reflux; ZO-1, zonula occludens 1 


\begin{tabular}{|llll|}
\hline \multicolumn{3}{|c|}{ Table 1} & \multicolumn{3}{l}{ Antibodies and their } & working dilutions \\
\hline $\begin{array}{l}\text { Antigen } \\
\text { specificity }\end{array}$ & Antibody type & Source & $\begin{array}{l}\text { Working } \\
\text { dilution }\end{array}$ \\
\hline E-cadherin & Mouse monoclonal & $\begin{array}{l}\text { Transduction } \\
\text { Laboratories }\end{array}$ & $1 / 1000$ \\
$\beta$ Catenin & Mouse monoclonal & $\begin{array}{l}\text { Transduction } \\
\text { Laboratories }\end{array}$ & $1 / 1000$ \\
Occludin & Mouse monoclonal & Zymed & $1 / 1000$ \\
ZO-1 & Rabbit polyclonal & Zymed & $1 / 1000$ \\
\hline ZO-1, zonula occludens 1. & & \\
\hline
\end{tabular}

department of otolaryngology at Southmead Hospital, Bristol. Approval was obtained from the local research ethics committee (reference 023/03).

\section{Preparation of microscopic specimens}

Specimens for light microscopy were immersion fixed in 10\% neutral buffered formalin, dehydrated with ethanol, cleared with xylene, and embedded in paraffin wax. Transverse sections $(4 \mu \mathrm{m})$ were prepared and affixed to poly-L-lysine coated slides (Sigma, Poole, Dorset, UK). Haematoxylin and eosin staining was used to localise tissue structures.

For electron microscopy, laryngeal sections were selected under a dissecting microscope; these sections were cut into rectangular pieces and immersed in $2 \%$ glutaraldehyde in $0.1 \mathrm{M}$ sodium cacodylate buffer $(\mathrm{pH} 7.2)$ for two hours. The tissue was postfixed in $1 \% \mathrm{OsO}_{4}$ in $0.1 \mathrm{M}$ sodium cacodylate buffer $(\mathrm{pH} 7.2)$ for one hour, rinsed in $0.1 \mathrm{M}$ sodium cacodylate three times (10 minutes each), and deionised water (10 minutes). Specimens were then dehydrated in an ascending series of ethanol, replaced with propylene oxide, and flat embedded in epoxy resin for 72 hours at $60^{\circ} \mathrm{C}$. Specific regions of the laryngeal tissue were located and identified using semithin sections (about $1 \mu \mathrm{m}$ ) stained with $0.5 \%$ toluidine blue in $0.5 \%$ borate. Thin sections $(0.1 \mu \mathrm{m})$ were cut, stained with 3\% uranyl acetate and lead citrate, and observed with a Phillips C200 electron microscope.

\section{Monoclonal antibodies}

Mouse monoclonal antibodies specific for E-cadherin and $\beta$ catenin were purchased from BD Transduction Laboratories (distributed by Affinity, Exeter, UK) and antibodies to occludin from Zymed (Cambridge Biosciences, Cambridge, UK). Table 1 provides details of the antibodies used.

\section{Immunohistochemistry}

For immunohistochemistry, serial sections $(4 \mu \mathrm{m})$ were dewaxed, rehydrated, and incubated with the previously validated mouse monoclonal antibodies to E-cadherin, $\beta$ catenin, occludin, and ZO-1 for one hour (table 1). Antigen retrieval was carried out for each antibody (microwaving in $0.01 \mathrm{M}$ citrate buffer). Endogenous peroxidase activity was blocked with 3\% hydrogen peroxide for 15 minutes. Antibody-antigen binding was detected using biotinylated goat and rabbit antimouse immunoglobulin (Dako, Glostrup, Denmark), followed by peroxidase conjugated streptavidin-biotin complex (Dako). Sites of peroxidase activity were demonstrated using 3,3'diaminobenzidine (DAB; Sigma) for up to 10 minutes. The primary antibody was omitted in the negative control sections. Sections were examined for nuclear, cytoplasmic, and membranous expression by two independent observers (GG, MP). Expression and subcellular localisation (membranous, cytoplasmic, or nuclear) was evaluated in stratified squamous epithelium and respiratory-type epithelium).
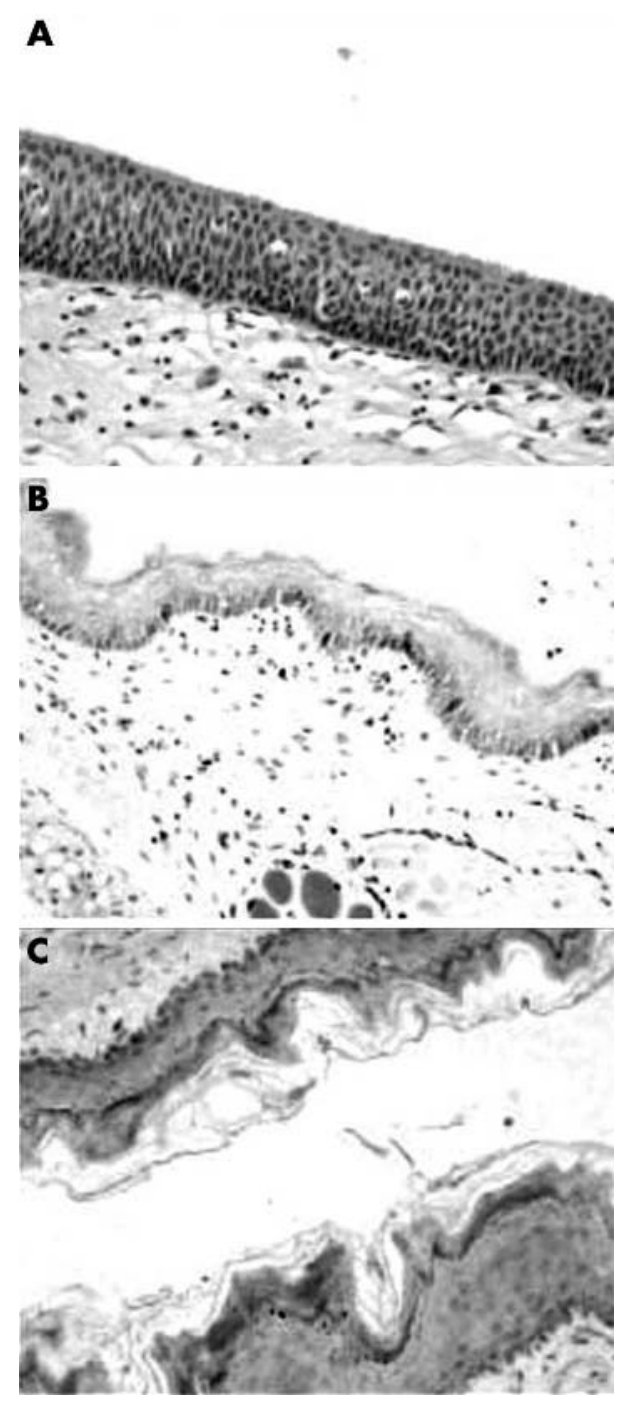

Figure 1 Morphological characterisation of human, rat, and mouse laryngeal mucosal tissue by haematoxylin and eosin staining. (A) In the human larynx, the surface epithelial cell layer consists of ciliated columnar epithelial cells. Vascular channels and scattered chronic inflammatory cells are seen in the subepithelial fibroconnective tissue. The squamous epithelium of the laryngeal mucosa is largely nonkeratinising and differs from rat sections (B). Respiratory-type epithelium was not seen in (B) rat or (C) mouse laryngeal tissue.

\section{Protein preparation from tissue samples and western blot procedure}

Tissue preparation

Protein extract was obtained by homogenisation of the tissue in lysis buffer containing 7M urea, 0.1 M dithiothreitol, 0.05\% Triton $\times 100,25 \mathrm{mM} \mathrm{NaCl}$, and $20 \mathrm{mM}$ Hepes, $\mathrm{pH} 7.6$. The extract was left on ice for 30 minutes and centrifuged at $10000 \times g$ for 15 minutes at $4^{\circ} \mathrm{C}$. The pellet was discarded and the supernatant snap frozen and stored at $-80^{\circ} \mathrm{C}$.

Proteins were resolved on $7.5 \%$ polyacrylamide gels and transferred to Immobilin P polyvinylidene difluoride membranes (Millipore, Watford, Hertfordshire, UK). Each lane of this gel received $80 \mu \mathrm{g}$ of protein. After electrophoresis and transfer to membrane (Bio-Rad, Hercules, California, USA) by electroblotting, blots were probed with specific primary and secondary antibodies. All antibodies were diluted 1/1000. Blots were subsequently probed with anti- $\alpha$ tubulin (Sigma, Poole, Dorset, UK) to demonstrate equal sample loading. Detection was achieved using a horseradish peroxidase 

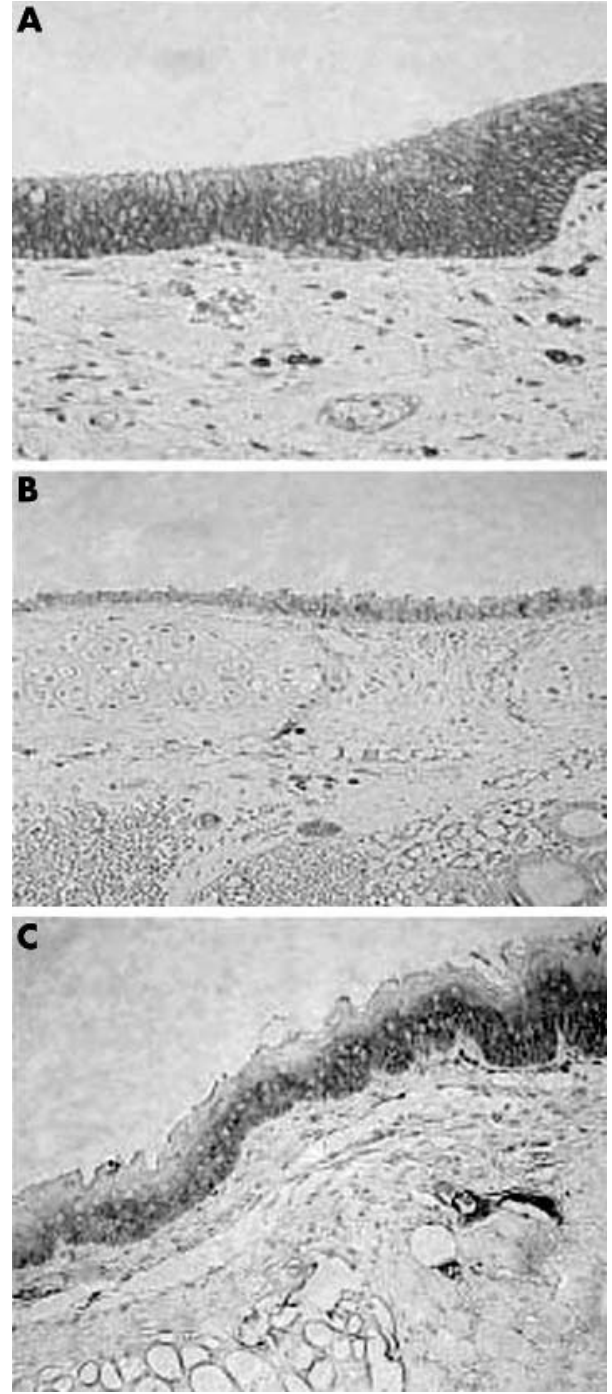

Figure 2 E-cadherin immunostaining in laryngeal epithelium from (A) human, $(B)$ mouse, and $(C)$ rat.

conjugated antimouse secondary antibody. An enhanced chemiluminescence detection system (Amersham, Arlington Heights, Illinois, USA) was used for signal development, according to the manufacturer's protocol.

\section{RESULTS}

Histological characterisation of the laryngeal epithelium (haematoxylin and eosin sections)

Laryngeal epithelium from pig, guinea pig, and rabbit primarily consisted of three predominant cell types: ciliated, secretory (mucin producing), and stratified squamous epithelial cells similar to those found in the human larynx. Rat and mouse larynx showed alterations in tissue structure compared with the human tissue; namely, the squamous epithelium was largely keratinised in rat sections and respiratory-type epithelium was not identified in either rat or mouse tissue (fig 1).

\section{Adherens and tight junction molecule expression and subcellular localisation}

We analysed the expression and subcellular localisation of Ecadherin and $\beta$ catenin in human and non-human larynx. In human larynx, E-cadherin was expressed over the entire intercellular membrane of the epithelial cells (fig 2A). The
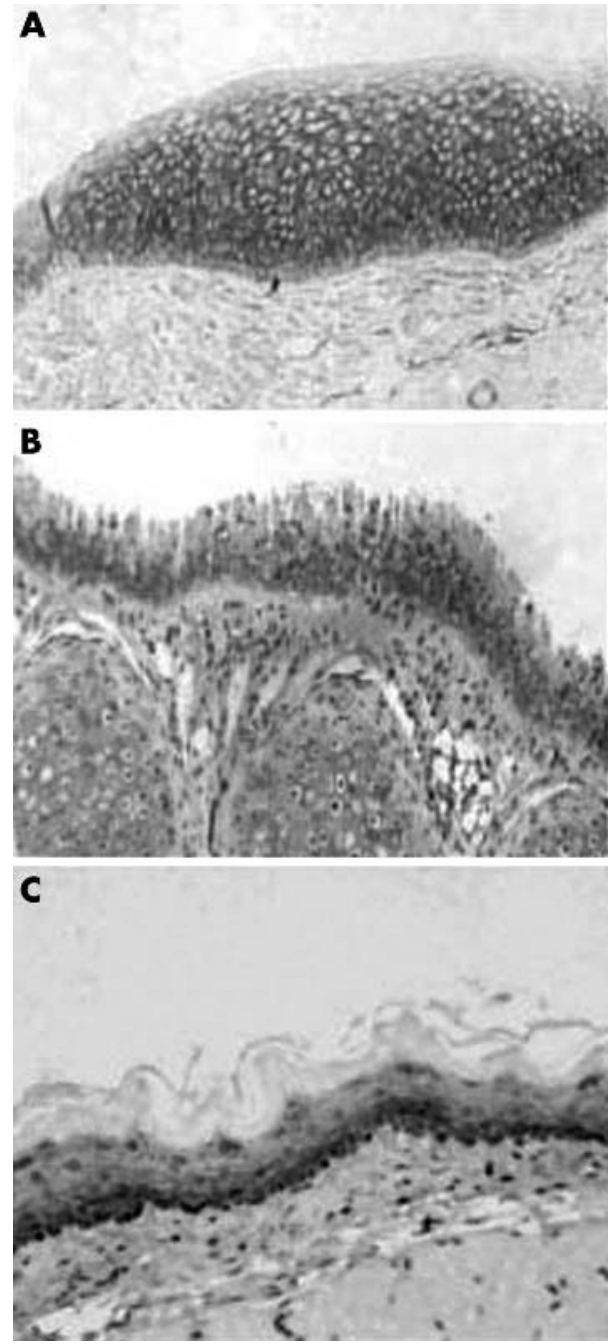

Figure 3 Immunostaining for $\beta$ catenin in laryngeal epithelium from (A) human, (B) mouse, and (C) rat.

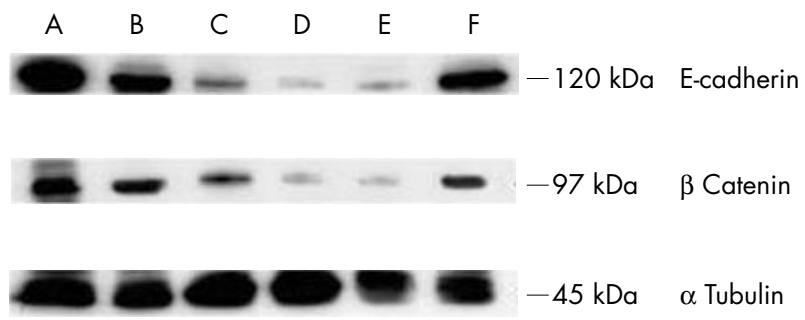

Figure 4 Western blot analysis of $\mathrm{E}$-cadherin and $\beta$ catenin. Normal laryngeal tissue from (A) human, (B) pig, (C) guinea pig, (D) rat, (E) mouse, and (F) rabbit; $\alpha$ tubulin was used as a loading control. Note the presence of low intensity bands for mouse and rat tissue compared with the other species.

distribution of this molecule in the stratified squamous epithelium decreased with maturation and expression was undetectable in the superficial layers (fig 2A). The staining pattern of E-cadherin was also membranous in all the nonhuman laryngeal samples studied. However, compared with that seen in humans, the mouse and rat showed weaker immunostaining for this complex (fig 2B, C). In all sections studied, $\beta$ catenin was present mainly in the membranous and to a lesser extent in the cytoplasmic cellular compartments. As 


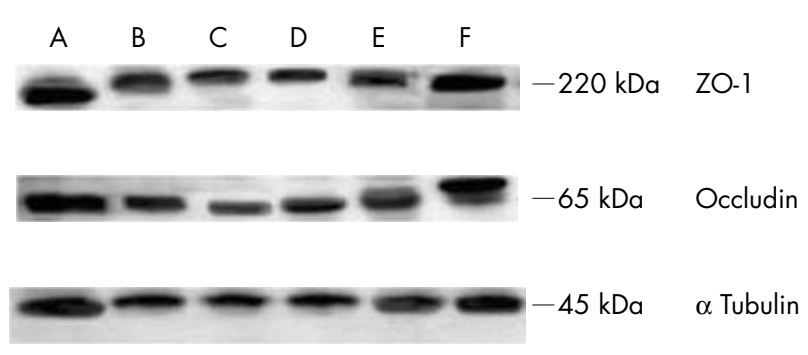

Figure 5 Western blotting analysis of zonula occludens 1 (ZO-1) and occludin. Normal laryngeal tissue from (A) human, (B) pig, (C) guinea pig, (D) rat, (E) mouse, and (F) rabbit; $\alpha$ tubulin was used as a loading control.

was seen for E-cadherin, immunoreactivity for $\beta$ catenin was less intense in rat and mouse laryngeal samples (fig 3). To confirm these results, we evaluated the total intracellular protein content of E-cadherin- $\beta$ catenin by western blotting. Indeed, we found low protein expression of both molecules in the samples from mouse and rat (fig 4).

\section{Tight junction expression}

We analysed the expression of the two tight junction molecules occludin and ZO-1 in human, mouse, rat, guinea pig, rabbit, and porcine tissue samples (fig 5). These molecules were expressed in all non-human species studied. In contrast to the Ecadherin-catenin complex, there was no difference in the total protein concentrations of occludin and ZO-1 between nonhuman and human tissues, as shown by western blotting.

\section{Ultrastructural study of human and porcine laryngeal epithelium}

Results obtained from histological and protein cellular expression studies clearly indicate that the porcine larynx is the most similar to the human larynx. For this reason, we investigated the ultrastructure of the porcine larynx by electron microscopy (fig 6A,B). We found stratified squamous and pseudostratified ciliated epithelium in the porcine larynx, similar to that found in human laryngeal sections. We noted a similar pattern of change in epithelial cell type from stratified squamous epithelial cells (supraglottic region) to pseudostratified, ciliated cells (subglottic region), as has been seen in human laryngeal tissue (fig 6C,D). The zonula adherens, zonula occludens, and desmosomal regions were similar in porcine and human tissue. Table 2 summarises the ultrastructural findings.

\section{DISCUSSION}

Our study investigated the anatomical and histopathological differences between the larynx in animals (pig, rabbit, guinea pig, rat, and mouse) and humans, with the aim of using the results to determine a suitable experimental model to study LPR. In this comparative study, we compared laryngeal anatomy and function of human and non-human species. We paid particular attention to essential adhesion structures (cadherin/catenins, ZO-1, and occludin) that may act as targets of acid refluxate. ${ }^{17}$ Acid and pepsin have been shown to break down the barrier function and epithelial permeability through perturbation of the junctional complex..$^{35}$ Both the protection and functional activity of the laryngeal epithelium rely upon structurally distinct cell categories,
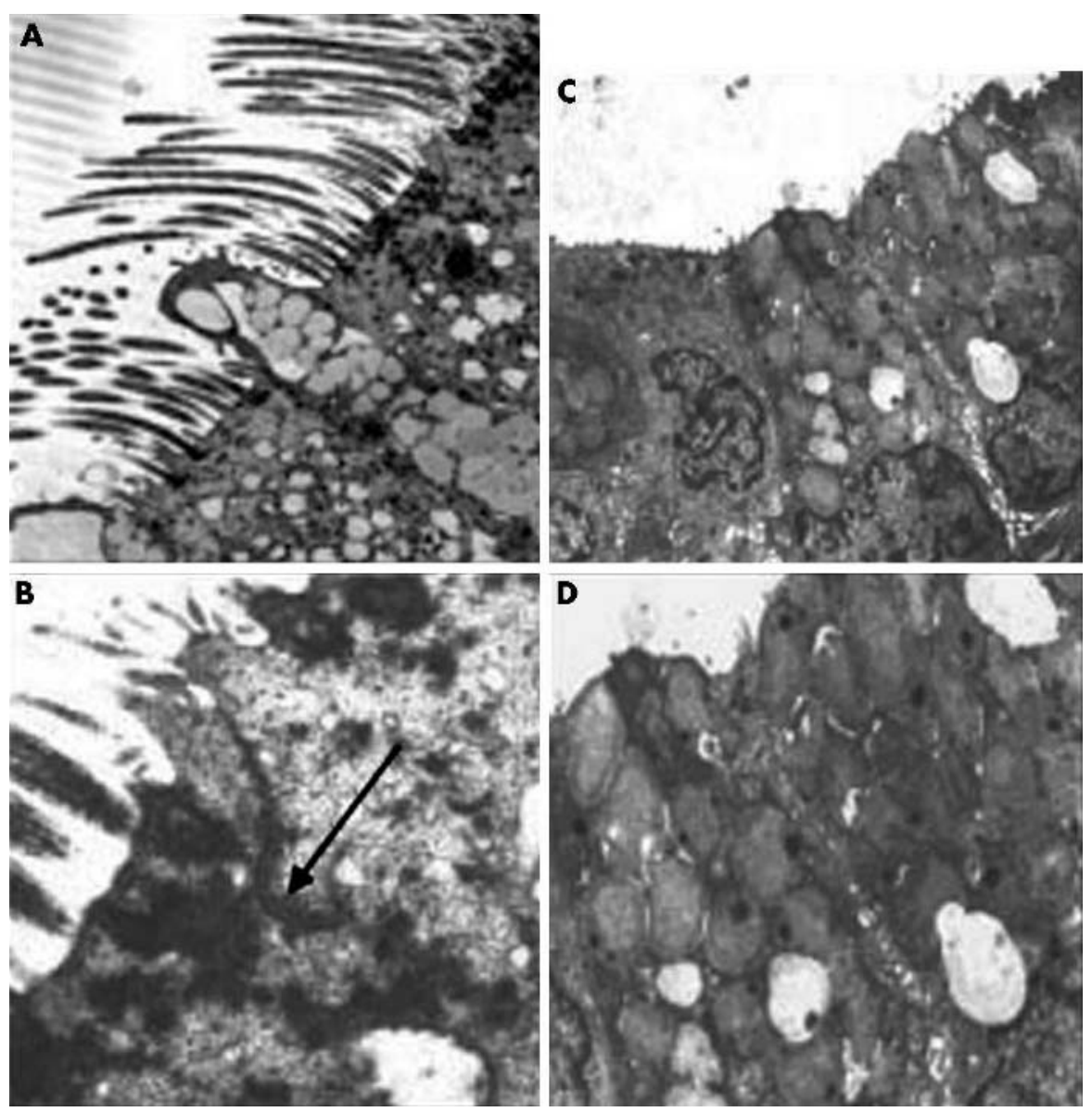

Figure 6 (A) Transmission electron micrograph of the apical region of ciliated columnar and goblet cells from the vocal fold of human larynx tissue (original magnification, $\times 5200$ ). (B) Cell membranes of adjacent ciliated cells closely apposed at the junctional complex (arrow) (original magnification, $\times 11600$ ). (C)

Transmission electron micrograph of the apical region of columnar epithelial and goblet cells from the porcine larynx (original magnification, $\times 5200$ ). (D) Cell membranes of adjacent cells closely apposed at the tight junctional complex (original magnification, $\times 11600)$. 
Table 2 Summary of ultrastructural results

\begin{tabular}{|c|c|c|c|c|c|}
\hline Species & Laryngeal histology & E-cadherin & $\beta$ Catenin & Occludin & ZO-1 \\
\hline Human & Stratified squamous epithelium; respiratory-type epithelium & $++(W)$ & $++(W)$ & (W) & $(W)$ \\
\hline Pig & Stratified squamous epithelium; respiratory-type epithelium & $+(\mathrm{W})$ & $++(\mathrm{W})$ & (W) & (W) \\
\hline Guinea pig & Stratified squamous epithelium & $+(W)$ & $+(\mathrm{W})$ & (W) & (W) \\
\hline Rat & Stratified squamous epithelium & $+(\mathrm{W})$ & $+(\mathrm{W})$ & (W) & (W) \\
\hline Mouse & Stratified squamous epithelium & $+(\mathrm{W})$ & $+(\mathrm{W})$ & (W) & (W) \\
\hline Rabbit & Stratified squamous epithelia; respiratory-type epithelium & $++(\mathrm{W})$ & $++(W)$ & (W) & (W) \\
\hline
\end{tabular}

E-cadherin and $\beta$ catenin immunohistochemistry was scored using a semiquantitative scoring system: + , weak expression; ++ , moderate expression as assessed by immunohistochemistry. (W), presence of protein as confirmed by western blot analysis. ZO-1, zonula occludens 1 .

and adherens junction and tight junction molecules play important roles.

E-cadherin plays an essential role in the structural and functional organisation of cells in tissues and organs of multicellular organisms. Sections from all non-human species showed uniform membranous E-cadherin staining patterns, similar to that seen in the normal human larynx. However we found differences in the total protein concentrations of E-cadherin, which was present in very low amounts in mouse and rat tissue. E-cadherin is able to bind the cytoskeleton through catenins. The presence of these catenins is therefore necessary for the full adhesive function of the cell. In the specimens examined, $\beta$ catenin was localised uniformly at the intercellular junctions of the epithelial cells at the apical-lateral cell membrane compartment. Similar to E-cadherin, we found reduced protein expression of $\beta$ catenin in rat and mouse tissue, as demonstrated by western blotting. It is possible that our findings may relate to specific antibody specificity to the different species investigated.

\section{"Our findings indicate that from an ultrastructural, anatomical, and morphological perspective, the porcine larynx is a superior model for research into epithelial damage occurring during laryngopharyngeal reflux"}

To our knowledge, there are no published data regarding the expression of tight junction molecules in the larynx. Occludin and ZO-1 are two integral membrane components that form tight junctions, especially in monolayers of epithelium derived tissues. In our study, we showed that in all species considered, ZO-1 and occludin were normally expressed and localised at the cell-cell contacts in the apical compartment. We confirmed the presence of these molecules by electron microscopy.

Our findings indicate that from an ultrastructural, anatomical, and morphological perspective, the porcine larynx is a superior model for research into epithelial damage occurring during LPR. We found that porcine tissue was the most comparable to human tissue because of the pattern of Ecadherin/catenin expression and the subcellular localisation.

\section{Take home messages}

- The expression of intercellular junctional complexes in porcine laryngeal epithelium is similar to that seen in humans

- The large size of the porcine larynx also offers a unique advantage over other models

- Thus, the porcine larynx is a suitable model for research into epithelial damage occurring during laryngopharyngeal reflux
The porcine larynx appears to be the most suitable to use in the development of an experimental model, in terms of practical use and similarity in tissue composition. The large size of the porcine larynx also offers a unique advantage over other models. Consequently, this animal model allows for the study of the common sites of reflux action seen in patients with LPR (supraglottic region and subglottic regions) within the same tissue sample.

Many different factors must be considered before selecting a suitable experimental model, in which the results can be translated to the clinical setting. Studying the pathological changes in the intercellular adhesion complexes after acid pepsin exposure could better characterise the molecular mechanisms involved in LPR. This aspect is currently under investigation in our laboratories, but additional studies are needed to determine the specific role of these ubiquitous molecules as clinical markers in the diagnosis of laryngeal reflux.

\section{ACKNOWLEDGEMENTS}

This study was supported by grants from BBSRC and Reckitt Benckiser Healthcare Ltd. The author gratefully acknowledges the assistance provided by Professor M Birchall and Dr P Brown, and G Tilly for her expertise with electron microscopy.

\section{Authors' affiliations}

G A Gill, A Buda, M Moorghen, M Pignatelli, Division of

Histopathology, Department of Pathology and Microbiology, School of Medical Sciences and Bristol Royal Infirmary, University of Bristol, Bristol BS2 8HW, UK

P W Dettmar, Department of Otolaryngology, Centre for Voice and Swallowing Disorders, Wake Forest University Health Sciences, Winston Salem, North Carolina, HUI 4BG, USA

\section{REFERENCES}

1 Amin MR, Postma GN, Johnson P, et al. Proton pump inhibitor resistance in the treatment of laryngopharyngeal reflux. Otolaryngol Head Neck Surg $2001 ; 125: 374-8$

2 Axford SE, Sharp N, Ross PE, et al. Cell biology of laryngeal epithelial defenses in health and disease: preliminary studies. Ann Otol Rhinol Laryngol 2001;110:1099-108.

3 Belafsky PC, Postma GN, Koufman JA. Laryngopharyngeal reflux symptoms improve before changes in physical findings. Laryngoscope 2001;111:979-81.

4 Koufman JA. Laryngopharyngeal reflux is different from classic gastroesophageal reflux disease. Ear Nose Throat J 2002;81(suppl 2):7-9

5 Cohen JT, Bach KK, Postma GN, et al. Clinical manifestations of laryngopharyngeal reflux. Ear Nose Throat J 2002;81(suppl 2):19-23.

6 Vaezi MF, Singh S, Richter JE. Role of acid and duodenogastric reflux in oesophageal mucosal injury: a review of animal and human studies. Gastroenterology 1995; 109:1897-907.

7 Beaver ME, Stesney CR, Weitzel E, et al. Diagnosis of laryngo pharyngeal reflux disease with digital imaging. Otolaryngol Head Neck Surg 2003;128:103-8.

8 Zalesska-Krecicka M, Krecicki T, Iwanczak B, et al. Laryngeal manifestations of gastroesophageal reflux disease in children. Acta Otolaryngol 2002;122:306-10.

9 Wiener GJ, Koufman JA, Wu WC, et al. Chronic hoarseness secondary to gastroesophageal reflux disease: documentation with 24-h ambulatory $\mathrm{pH}$ monitoring. Am J Gastroenterol 1989;84:1503-18.

10 Orlando RC. Pathogenesis of gastroesophageal reflux disease. Am J Med Sci 2003;326:274-8 
11 Hicks DM, Ours TM, Abelson TI, et al. The prevalence of hypopharynx findings associated with gastroesophageal reflux in normal volunteers. J Voice 2002; 16:564-79

12 Lanas A, Royo Y, Ortego J, et al. Experimental esophagitis induced by acid and pepsin in rabbits mimicking human reflux esophagitis. Gastroenterolology 1999;116:97-107.

13 Tobey NA, Koves G, Orlando RC. HCl-induced cell edema in primary cultured rabbit esophageal epithelium. Gastroenterology 1997; 1 12:847-54.

14 Lanas A, Sousa FL, Ortego J, et al. Aspirin renders the esophageal mucosa more permeable to acid and pepsin in rabbits by different mechanisms. Eur J Gastroenterol Hepatol 1995;7:1065-72.

15 Schweitzer EJ, Bass BJ, Johnson LF, et al. Sucralafate prevents experimental esophagitis in rabbits. Gastroenterology 1985;88:611-19.

16 Tay HP, Chaparala RC, Harmon JW, et al. Bismuth subsalicylate reduces peptic injury of the oesophagus in rabbits. Gut 1990;31:11-16.

17 Johnston N, Bulmer D, Gill GA, et al. Cell biology of laryngeal epithelial defenses in health and disease: further studies. Ann Otol Rhinol Laryngol 2003;1 12:481-91.

18 Chen X, Kojima S, Borisy GG, et al. pl 20 catenin associates with kinesin and facilitates the transport of cadherin-catenin complexes to intercellular junctions. J Cell Biol, 200310, 163:547-57.

19 Guo X, Rao JN, Liu L, et al. Regulation of adherens junctions and epithelial paracellular permeability: a novel function for polyamines. Am J Physiol Cell Physiol 2003;285:C1174-87.

20 Cereiiido M, Shoshani L, Contreras RG. Molecular physiology and pathophysiology of tight junctions. I Biogenesis of tight junctions and epithelial polarity. Am J Physiol Gastrointest Liver Physiol 2000;279:G477-82.

21 Collares-Buzato CB, McEwan GT, Jepsom MA, et al. Paracellular barrier and junctional protein distribution depend on basolateral extracellular $\mathrm{Ca}^{2+}$ in cultured epithelia. Biochim Biophys Acta 1994;1222:147-58.
22 Takeichi M. Cadherins: a molecular family important in selective cell-cell adhesion. Annu Rev Biochem 1990;53:237-52.

23 Yap AS, Brieher WM, Gumbiner BM. Molecular and functional analysis of cadherin-based adherens junctions. Ann Rev Cell Dev Biol 1997;13:1 19-46.

24 Takeichi M. Morphogenetic roles of classic cadherins. Curr Opin Cell Biol 1995;7:619-27.

25 Gumbiner BM. Cell adhesion: the molecular basis of tissue architecture and morphogenesis. Cell 1996:84:345-57.

26 Gumbiner BM. Regulation of cadherin adhesive activity. J Cell Biol 2000; 148:399-404

27 Palacios E, Friedlander PL. Chondosarcoma of the larynx. Ear Nose Throat J 2002;81:83.

28 Mitic LL, Anderson JM. Molecular architecture of tight junctions. Annu Rev Physiol 1998;60:121-42.

29 Rodriguez-Boulan E, Nelson WJ. Morphogenesis of the polarized epithelial cell phenotype. Science 1989;245:718-25.

30 Schneeberger EE, Lynch RD. Structure, function and regulation of cellular tight junctions. Am J Physiol 1992;262:L647-61.

31 Gumbiner BM. Structure, biochemistry and assembly of epithelial tight junctions. Am J Physiol 1987;253:C749-58.

32 Gumbiner BM. Breaking through the tight junction barrier. J Cell Biol 1993; 120:3667-79

33 Furuse $M$, Hirase $T$, Itoh $M$, et al. Occludin: a novel integral membrane protein localizing at tight junctions. J Cell Biol 123:1777-88.

34 Ando-Akatsuka Y, Saitou M, Hirase T, et al. Interspecies diversity of the occluding sequence: cDNA cloning of human, mouse, dog and rat-kangaroo homologues. J Cell Biol 1996;133:43-7.

35 Tobey NA, Hosseini SS, Caymaz-Bor C, et al. The role of pepsin in acid injury to esophageal epithelium. Am J Gastroenterol 2001;96:3062-70. 